\title{
Axitinib in combination with radiotherapy for advanced hepatocellular carcinoma: a phase I clinical trial
}

\author{
Kai-Lin Yang ${ }^{1,2}$, Mau-Shin Chi ${ }^{1}$, Hui-Ling Ko ${ }^{1}$, Yi-Ying Huang ${ }^{1}$, Su-Chen Huang ${ }^{1}$, Yu-Min Lin ${ }^{2,3}$ \\ and Kwan-Hwa Chi ${ }^{1,4^{*}}$
}

\begin{abstract}
Background: To investigate maximum tolerated dose (MTD) of axitinib, a selective vascular endothelial growth factor receptor 1-3 inhibitor, in combination with radiotherapy (RT) for advanced hepatocellular carcinoma (HCC).

Methods: This phase I study followed the rule of traditional $3+3$ design. Major eligibility included: (1) patients with advanced HCC unsuitable for surgery, radiofrequency ablation or transarterial chemoembolization, or who failed after prior local-regional treatment; (2) failure on sorafenib or no grant for sorafenib from health insurance system. Eligible patients with advanced HCC received axitinib for total 8 weeks during and after RT. Three cohorts with axitinib dose escalation were planned: $1 \mathrm{mg}$ twice daily (level I), $2 \mathrm{mg}$ twice daily (level II) and $3 \mathrm{mg}$ twice daily (level III). The prescribed doses of RT ranged from 37.5 to 67.5 Gy in 15 fractions to liver tumor(s) and were determined based on an upper limit of mean liver dose of $18 \mathrm{~Gy}$ (intended isotoxic RT for normal liver). The primary endpoint was MTD of axitinib in combination with RT. The secondary endpoints included overall response rate (ORR), RT in-field response rate, acute and late toxicities, overall survival (OS) and progression free survival (PFS).

Results: Total nine eligible patients received axitinib dose levels of $1 \mathrm{mg}$ twice daily $(n=3), 2 \mathrm{mg}$ twice daily $(n=3)$ and $3 \mathrm{mg}$ twice daily $(n=3)$. Dose-limiting toxicity (DLT) did not occur in the 3 cohorts; the MTD was defined as $3 \mathrm{mg}$ twice daily in this study. ORR was 66.7\%, including 3 complete responses and 3 partial responses, at 3 months after treatment initiation. With a median follow-up of 16.6 months, median OS was not reached, 1 -year OS was $66.7 \%$, and median PFS was 7.4 months.
\end{abstract}

Conclusions: Axitinib in combination with RT for advanced HCC was well tolerated with an axitinib MTD of 3 mg twice daily in this study. The outcome analysis should be interpreted with caution due to the small total cohort.

Trial registration ClinicalTrials.gov (Identifier: NCT02814461), Registered June 27, 2016—Retrospectively registered, https://clinicaltrials.gov/ct2/show/NCT02814461

Keywords: Advanced hepatocellular carcinoma, Axitinib, Maximum tolerated dose, Radiotherapy

\footnotetext{
*Correspondence: M006565@ms.skh.org.tw

1 Department of Radiation Therapy and Oncology, Shin Kong Wu Ho-Su

Memorial Hospital, Shih-Lin District, No. 95, Wen-Chang Road, Taipei

City 111, Taiwan

Full list of author information is available at the end of the article
}

\begin{abstract}
Background
The management of inoperable hepatocellular carcinoma $(\mathrm{HCC})$ is challenging. Local ablation treatments including radiofrequency ablation (RFA) or other ablative approaches can typically achieve excellent local control for tumors less than $3 \mathrm{~cm}[1,2]$. For large or multifocal tumors, regional therapy with transarterial chemoembolization (TACE) are commonly recommended. In
\end{abstract} original author(s) and the source, provide a link to the Creative Commons licence, and indicate if changes were made. The images or other third party material in this article are included in the article's Creative Commons licence, unless indicated otherwise in a credit line to the material. If material is not included in the article's Creative Commons licence and your intended use is not permitted by statutory regulation or exceeds the permitted use, you will need to obtain permission directly from the copyright holder. To view a copy of this licence, visit http://creativecommons.org/licenses/by/4.0/. The Creative Commons Public Domain Dedication waiver (http://creativeco mmons.org/publicdomain/zero/1.0/) applies to the data made available in this article, unless otherwise stated in a credit line to the data. 
randomized studies, patients receiving TACE had better survival than those treated with only symptomatic treatment $[3,4]$. However, either local ablation or TACE is sometimes contraindications for reasons, such as large tumor size, large number, inadequate location, macrovascular involvement, or impaired liver function [4-9].

Advances in radiotherapy (RT) technique have made RT become more important in the treatment of inoperable HCC [10-24]. For example, intensity-modulated radiotherapy (IMRT) has improved conformity of tumor dose and can spare critical normal organs better, while imageguided radiotherapy (IGRT) and breathing motion management allow accurate RT delivery by reducing setup error and effect of breathing cycle on liver location [25, 26]. These together also lead to an emerging role of stereotactic ablative body radiotherapy (SABR) in HCC [27]. Considering tumor size and normal tissue tolerance, radiation doses have ranged widely. Therefore, for advanced HCC treated with RT, the outcomes were reported in a wide range, including local control from 50 to $70 \%$ and median survival from 6 to 18 months. Higher radiation doses, hypofractionated RT or SABR may improve these treatment outcomes. However, first recurrence was usually identified at an intrahepatic site beyond irradiated field [28]. A treatment strategy combining RT with systemic therapy may be indicated.

Sorafenib, a multi-kinase inhibitor against angiogenesis and tumor proliferation, has become the standard systemic therapy for advanced HCC after two randomized controlled trials proved better survival of patients treated with sorafenib than placebo [29, 30]. Regorafenib, another multi-kinase inhibitor similar to sorafenib, was approved as a second-line treatment for HCC after failure from sorafenib [31]. Lenvatinib, a new multi-kinase inhibitor, was recently approved as another first-line treatment of HCC after a randomized phase III study proved non-inferiority in term of overall survival compared with sorafenib [32]. However, a substantial portion of patients treated with these kinase inhibitors encountered intrahepatic progression eventually. It has been believed that adding local treatment to effective systemic therapy may possibly consolidate at least local therapeutic effect. Sorafenib in combination with RT was considered effective in tumor response [33, 34], but potential hepatic toxicities may undermine the benefit of the strategy [35].

At the timepoint when our present study was initiated, sorafenib was the only approved targeted therapy for advanced HCC. Meanwhile, axitinib, a potent kinase inhibitor selectively inhibiting vascular endothelial growth factor (VEGF) receptors 1, 2 and 3, demonstrated superior outcomes for renal cell carcinoma (RCC) when compared with sorafenib, and thus axitinib was approved as second-line treatment for advanced RCC after failure of prior treatment with sunitinib or a cytokine [36]. $\mathrm{HCC}$ and RCC are both hypervascular cancers that can be potentially controlled by angiogenesis inhibitor. Axitinib was also studied for HCC in some clinical trials. In a randomized placebo-controlled phase II trial for locally advanced or metastatic HCC who failed from sorafenib, axitinib improved progression-free survival and showed overall response rate of $9.7 \%$, but did not demonstrated benefit in overall survival [37]. Another phase II trial also reported second-line axitinib showed encouraging response rate with well tolerability [38].

Preclinical studies suggested axitinib can increase apoptosis of tumor endothelial cells after RT in vitro [39]. Some in vivo studies also demonstrated axitinib may effectively and safely improve tumor control with RT $[39,40]$. Axitinib in combination with RT seems to be a potential approach. We hypothesized RT combined with axitinib would be safe and effective for advanced HCC, but the safety profile is not yet established. This phase I study aimed at determining the safety and maximum tolerated dose (MTD) of axitinib in combination with radiotherapy for advanced hepatocellular carcinoma.

\section{Methods}

This phase I study was approved by the institutional review board (No. 20150704 M) and was registered in ClinicalTrials.gov (Identifier: NCT02814461). Patients with advanced HCC unsuitable for resection, liver transplantation, RFA or TACE, or who failed after prior local-regional treatment were eligible. Other key eligibility criteria included failure on sorafenib or no grant for sorafenib from health insurance system, Child-Pugh score A or B, and ECOG performance status 0-2. Multiple tumors, portal vein thrombosis, regional lymph node metastasis or distant metastasis was allowed. Major exclusion criteria included high risk of bleeding (e.g. active peptic ulcer, unstable esophageal/gastric varices, history of aneurysm, and requirement of anticoagulant therapy) and pre-existing uncontrolled hypertension (systolic $>140 \mathrm{mmHg}$, diastolic $>90 \mathrm{mmHg}$ ) or proteinuria $\geq 500 \mathrm{mg} / 24 \mathrm{~h}$.

This phase I study followed the rule of traditional $3+3$ design, and dose escalation of axitinib was conducted with 3 dose levels: $1 \mathrm{mg}$ twice daily (level I), $2 \mathrm{mg}$ twice daily (level II) and $3 \mathrm{mg}$ twice daily (level III). Because the interaction between axitinib and RT was not well known before this study, the starting dose of axitinib was set at a minimal dose of $1 \mathrm{mg}$ twice daily for the best of safety. The regimen of RT was 37.5 to 67.5 Gy in 15 fractions in 3 weeks (2.5 to 4.5 Gy per fraction) to liver tumor(s) (e.g. portal vein thrombosis, tumors with size $\geq 3 \mathrm{~cm}$, or recurrent/refractory tumors). The final prescribed dose 
of RT was based on an upper limit of mean liver dose of $18 \mathrm{~Gy}$ for all plans (intended isotoxic RT for normal liver). Daily Entecavir $0.5-1 \mathrm{mg}$ or Telbivudine $600 \mathrm{mg}$ was recommended for patients with hepatitis B during and 3 months after RT. The primary endpoint was MTD of axitinib in combination with RT for advanced HCC. Secondary endpoints included overall response rate (ORR), RT in-field response rate, acute and late toxicities, overall survival (OS) and progression free survival (PFS). The RT in-field response rate was defined as the response rate of the irradiated tumor(s) within planning target volume of RT.

Dose-limiting toxicity (DLT) was defined as, according to the Common Terminology Criteria for Adverse Events (CTCAE) version 4.0, any of the following when considered related to protocol treatment: any grade 4 or 5 toxicities, grade 3 gastrointestinal toxicity despite the use of medical intervention and/or prophylaxis, grade 3 anemia, or grade 3 nonhematologic toxicities except nausea, vomiting, diarrhea, constipation, pain, and hypertension controlled with medication. In the beginning of the study, the first 3 patients were treated at starting dose of axitinib with $1 \mathrm{mg}$ twice daily, and the next step would follow the rule described here. In order to observe any acute or delayed toxicities, our investigators waited for at least 3 months before moving to subsequent dose levels. If DLT was observed in 0 of 3 patients at a given dose level, the study would enter the next higher dose level. If DLT developed in $\geq 2$ of 3 patients, the study would return to the next lower dose level if any. If DLT was noticed in 1 of 3 patients at a given dose level, additional 3 patients would be needed at this dose level. If DLT was noticed in 1 patient of the expanded 6-patient cohort, the study proceeded to the next higher level. If DLT developed in $\geq 2$ patients of the expanded 6-patient cohort, the trial would proceed to the next lower dose level if any. When there were only 3 patients in the next lower dose level, 3 additional patients would be enrolled; while 6 patients are already there, the phase I trial would be stopped. MTD is defined as the dose at which $\leq 1 / 6$ encounters DLT. It was estimated that about 9 to 18 patients would be enrolled in the phase I study. At least 3 months of follow-up after completion of protocol treatment should be performed to allow an adequate observation of DLT occurrence.

The descriptive statistics were summarized as percentages for proportions and as median (with ranges in parentheses) for continuous values. By response evaluation criteria in solid tumors (RECIST) version 1.1 [41], the response were evaluated by a radiologist at 3 months after treatment initiation. Survival curves were analyzed by Kaplan-Meier method, using Log-rank test when determining statistical significance of difference between subgroups. A $p$ value $<0.05$ (two-tailed) would be considered statistically significant. All statistical analyses were performed using Statistical Package for Social Sciences software version 20 (SPSS, Inc, Chicago, IL).

\section{Results}

During the phase I study, total nine patients were enrolled. Among the total 9 patients, median age was 72 years (range $37-83$ years), $88.9 \%$ were male, $78 \%$ had Child-Pugh class A, and $67 \%$ had hepatitis B or C (Table 1). At baseline, 33\% had multiple liver tumors, $33 \%$ had portal vein thrombosis, none had lymph node metastasis, $11 \%$ had distant metastasis, and the median of liver tumor maximum diameter was $6.6 \mathrm{~cm}$ (Table 1). Each 3 patients subsequently entered cohorts of axitinib dose levels: $1 \mathrm{mg}$ twice daily $(\mathrm{n}=3), 2 \mathrm{mg}$ twice daily $(\mathrm{n}=3)$ and $3 \mathrm{mg}$ twice daily $(\mathrm{n}=3)$. Dose-limiting toxicity (DLT) did not occur in the 3 cohorts (Table 2), and

\section{Table 1 Patient and tumor characteristics at baseline $(n=9)$}

\begin{tabular}{ll}
\hline Age, years, median (range) & $72(37-83)$ \\
Gender (male: female) & $8: 1$ \\
ECOG performance status & \\
0 & $1(11 \%)$ \\
1 & $8(89 \%)$ \\
Child-Pugh score & \\
5 (class A) & $4(45 \%)$ \\
6 (class A) & $3(33 \%)$ \\
7 (class B) & $2(22 \%)$ \\
Etiology of HCC & \\
Hepatitis B virus (HBV) & $5(56 \%)$ \\
Hepatitis C virus (HCV) & $1(11 \%)$ \\
Non-HBV, non-HCV & $3(33 \%)$ \\
BCLC staging & \\
B & $1(11 \%)$ \\
C & $8(89 \%)$ \\
Number of liver tumor(s) & \\
Single & $6(67 \%)$ \\
Multiple & $3(33 \%)$ \\
Portal vein thrombosis & \\
Present & \\
Absent & $3(33 \%)$ \\
Regional lymph node metastasis & $6(67 \%)$ \\
Present & \\
Absent & \\
Distant metastasis & $0(0 \%)$ \\
Present & $9(100 \%)$ \\
Absent & \\
Maximum diameter of liver tumor, cm, median (range) \\
RT doses, Gy, median (range) & $45(37.5-53)$ \\
\hline
\end{tabular}


Table 2 Toxicities

\begin{tabular}{|c|c|c|c|c|c|c|c|c|}
\hline & \multicolumn{2}{|l|}{ Total $(n=9)$} & \multicolumn{2}{|c|}{ Level I cohort $(n=3)$} & \multicolumn{2}{|c|}{ Level II cohort $(n=3)$} & \multicolumn{2}{|c|}{ Level III cohort $(n=3)$} \\
\hline & Grade 1-3 & Grade 3 & Grade 1-3 & Grade 3 & Grade 1-3 & Grade 3 & Grade 1-3 & Grade 3 \\
\hline Leucopenia & 4 & 0 & 0 & 0 & 2 & 0 & 2 & 0 \\
\hline Anemia & 1 & 0 & 1 & 0 & 0 & 0 & 0 & 0 \\
\hline Thrombocytopenia & 4 & 0 & 0 & 0 & 2 & 0 & 2 & 0 \\
\hline Increased ALT & 5 & 0 & 2 & 0 & 1 & 0 & 2 & 0 \\
\hline Increased alkaline-P & 6 & 0 & 3 & 0 & 0 & 0 & 3 & 0 \\
\hline Increased total bilirubin & 6 & 0 & 2 & 0 & 1 & 0 & 3 & 0 \\
\hline Increased creatinine & 2 & 0 & 1 & 0 & 1 & 0 & 0 & 0 \\
\hline Hypothyroidism & 3 & 0 & 1 & 0 & 0 & 0 & 2 & 0 \\
\hline Proteinuria & 6 & 0 & 2 & 0 & 1 & 0 & 3 & 0 \\
\hline Skin rash & 1 & 0 & 0 & 0 & 0 & 0 & 1 & 0 \\
\hline Hand numbness & 1 & 0 & 1 & 0 & 0 & 0 & 0 & 0 \\
\hline Hypertension & 9 & 5 & 3 & 1 & 3 & 2 & 3 & 2 \\
\hline Nausea/vomiting & 1 & 1 & 1 & 1 & 0 & 0 & 0 & 0 \\
\hline Diarrhea & 3 & 2 & 1 & 1 & 1 & 1 & 1 & 0 \\
\hline Constipation & 2 & 0 & 1 & 0 & 1 & 0 & 0 & 0 \\
\hline
\end{tabular}

Table 3 Tumor response to axitinib in combination with radiotherapy $(n=9)$

\begin{tabular}{lll}
\hline & Overall response & RT in-field response \\
\hline Complete response (CR) & $3(33.3 \%)$ & $4(44.4 \%)$ \\
Partial response (PR) & $3(33.3 \%)$ & $3(33.3 \%)$ \\
Stable disease (SD) & $0(0 \%)$ & $0(0 \%)$ \\
Progressive disease (PD) & $3(33.3 \%)$ & $2(22.2 \%)$ \\
Response rate (CR +PR) & $6(66.7 \%)$ & $7(77.8 \%)$ \\
\hline
\end{tabular}

the MTD was defined as $3 \mathrm{mg}$ twice daily in this study. The most common adverse events (AEs) occurring in patients receiving axitinib (all grades) were hypertension, proteinuria, increased alanine transaminase (ALT), increased alkaline phosphatase (ALK-P), and increased bilirubin. The most common grade 3 AEs were hypertension, which could be managed by anti-hypertensive agents. Other grade 3 AEs included nausea, vomiting and diarrhea, which were all manageable. Among all patients, no grade 4 or 5 AEs occurred.

Among all 9 patients, overall response rate by RECIST criteria was $66.7 \%$, including 3 complete responses (CR) and 3 partial responses (PR), at 3 months after treatment initiation (Table 3 \& Fig. 1a). RT in-field response rate was $77.8 \%$ (4 CR and 3 PR) (Table 3 and Fig. 1b). The axitinib dose levels were not associated with tumor response $(p=0.406)$. Figure 2 illustrated one patient with $\mathrm{CR}$ with $\mathrm{CT}$ scans before and after RT in combination with axitinib $1 \mathrm{mg}$ twice daily.
With a median follow-up of 16.6 months, median overall survival (OS) was not reached, 1-year OS was $66.7 \%$ (Fig. 3), and median progression-free survival (PFS) was 7.4 months (Fig. 4). On univariate analysis, responders $(p=0.024)$ and Child-Pugh A $(p=0.018)$ were associated with favorable OS. Responders $(p=0.002)$ and ChildPugh A $(p=0.002)$ were also associated with favorable PFS.

\section{Discussion}

Anti-angiogenic agents or transarterial therapies proved therapeutic value for $\mathrm{HCC}$, a hypervascular cancer. Combination of some anti-angiogenic agents and RT showed potential benefit at both pre-clinical and clinical level [39, 40, 42-45]. In pre-clinical studies, anti-angiogenesis may allow better maturation of cancer blood vessels, and could potentially improve tumor oxygenation and thus tumoricidal effect of RT [46, 47]. According to in vitro and in vivo studies, axitinib can improve tumor control of RT by radiosensitizing tumor endothelial cells [39], and xenograft lung tumors on mice treated with axitinib and RT impressively showed complete tumor response and even reduced lung toxicity compared with $\mathrm{RT}$ or axitinib alone [40]. In our study, the response rate of axitinib in combination with RT is encouraging. This could be contributed by radiosensitization effect from addition of axitinib.

The safety of axitinib in combination with RT was not yet established before our study. Following a principle of the best safety, the starting dose of axitinib in our present phase I study was set as a minimal practicable dose of 
a Overall tumor response of individual patients

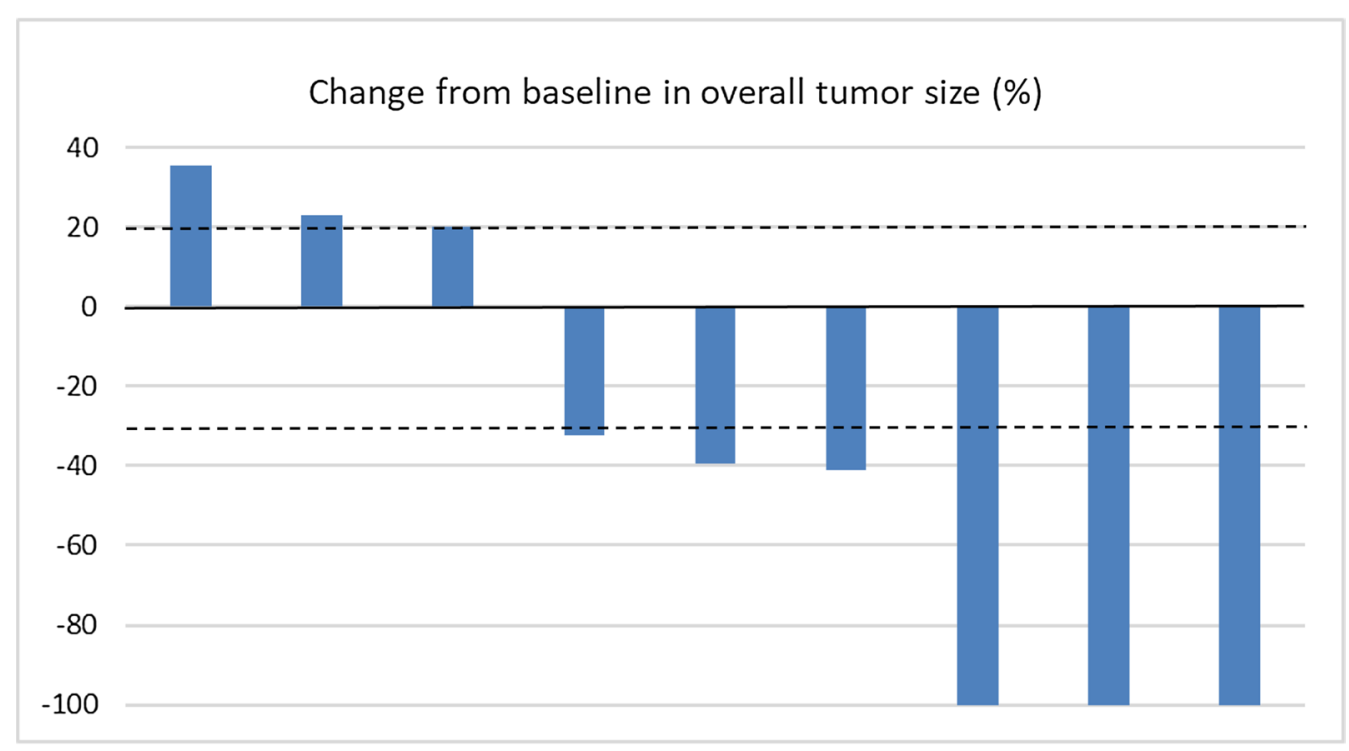

b RT in-field tumor response of individual patients

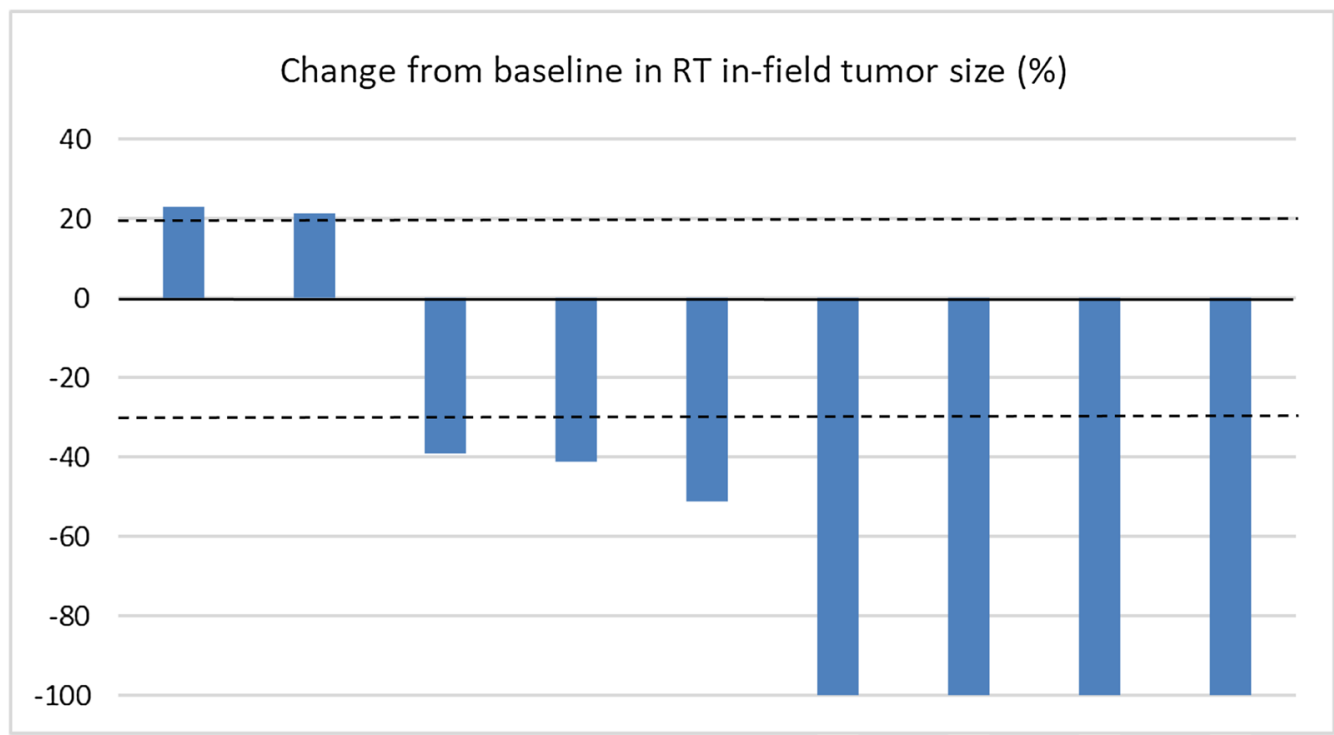

Fig. 1 Waterfall plot for percentage change in tumor size at 3 months after treatment initiation. The dashed line at 20\% means the cut-off value for progressive disease, and the dashed line at $-30 \%$ for determination of means the cut-off value for partial response. a Overall tumor response of individual patients. b RT in-field tumor response of individual patients

$1 \mathrm{mg}$ twice daily, and the dose would be escalated by a relatively safe dose interval. In addition, we intended to deliver isotoxic and safe RT to normal liver with similar mean liver doses approaching 18 Gy for each patient. Although this caused heterogeneous prescribed RT dose in our study, this would be a necessary measure to make RT toxicities relatively constant and could enable appropriate evaluation of tolerability regarding axitinib MTD in combination with RT.
Our study successfully proved that axitinib in combination with RT is safe at least up to the dose of axitinib $3 \mathrm{mg}$ twice daily, which was considered as the MTD in this study. The dose is already within the recommended dose range of axitinib: $2 \mathrm{mg}$ twice daily to $10 \mathrm{mg}$ twice daily adjusted according to individual tolerability [36, 48, 49]. According to our data, no additional toxicities were induced by the combination of RT and axitinib. All the AEs did not exceed grade 3 and were all manageable. We 


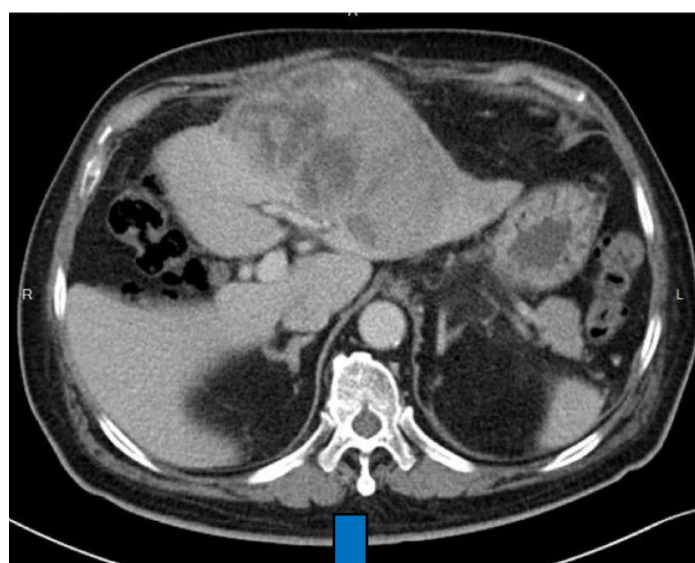

\section{CT scan before treatment with}

RT and axitinib

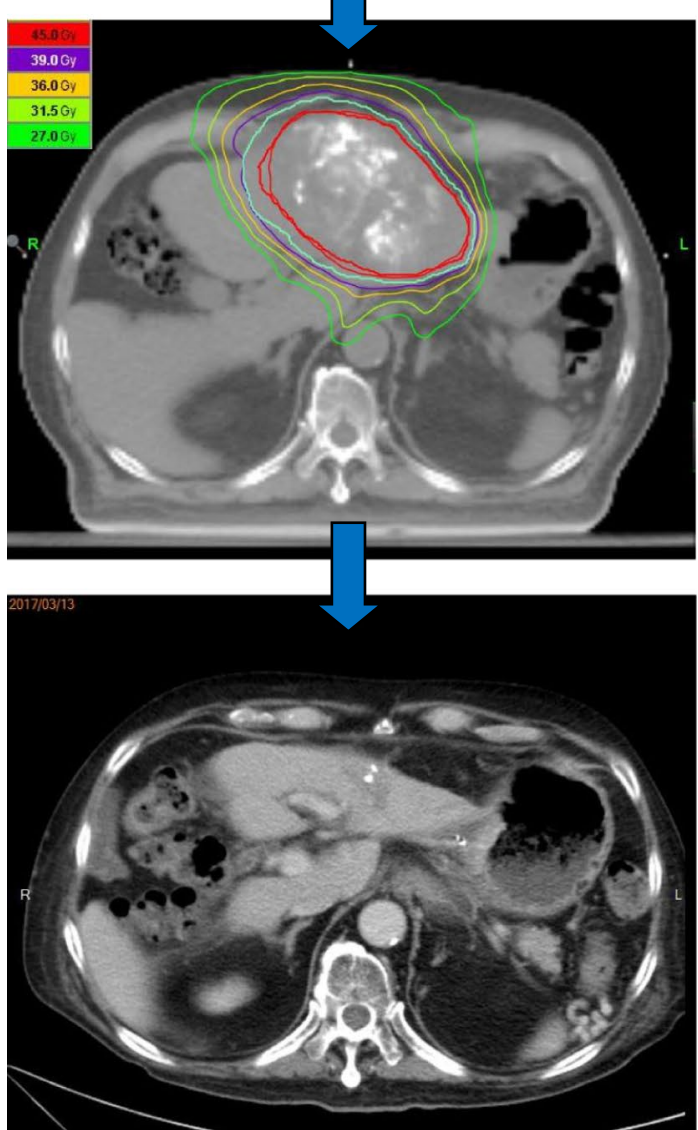

RT 45 Gy in 15 fractions in 3 weeks

(RT treatment plan as illustrated) $+$

axitinib $1 \mathrm{mg}$ twice daily for 2 months

\section{CT scan at 3 months after}

initiation of treatment with

RT and axitinib

Fig. 2 A case presentation (complete response, long-term alive, no recurrence). A 72-year-old man, with liver cirrhosis Child-Pugh class A (non-HBV, non-HCV related), was diagnosed as having a 12-cm HCC in left lobe of liver with classical enhancement pattern and involvement of left portal vein by CT scan in August 2016, clinically staged as CT3bNOMO, BCLC stage C. High alpha-fetoprotein (AFP) up to $160.1 \mathrm{ng} / \mathrm{ml}$ was noted. TACE failed with only partial obliteration of tumor vessels. He was then eligible for this phase I trial. He received RT with 45 Gy in 15 fractions plus axitinib 1 mg twice daily for 2 months. The patient tolerated the treatment well. At 3 months after RT initiation, follow-up CT scan revealed complete response of the tumor, and AFP decreased to $1.9 \mathrm{ng} / \mathrm{ml}$. In 2020, the patient is still regularly followed up without recurrence

did not further escalate the dose because we had only limited resources for this study. If any other study groups want to conduct another similar phase I study, a starting dose with axitinib $3 \mathrm{mg}$ twice daily can be considered. A determined MTD will facilitate design of a phase II study evaluating efficacy.

Clinical experiences with RT and anti-angiogenic agent showed some encouraging results. One retrospective 


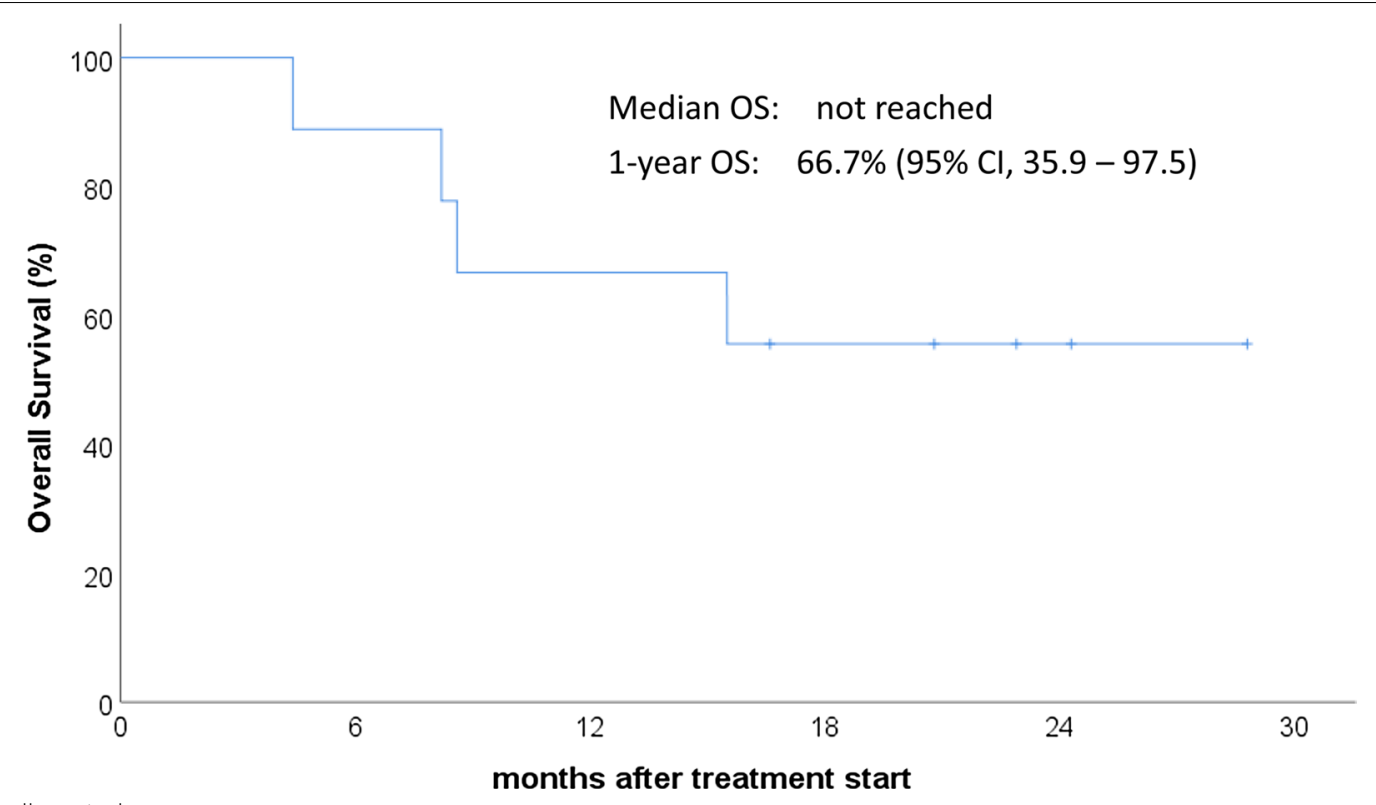

Fig. 3 Overall survival

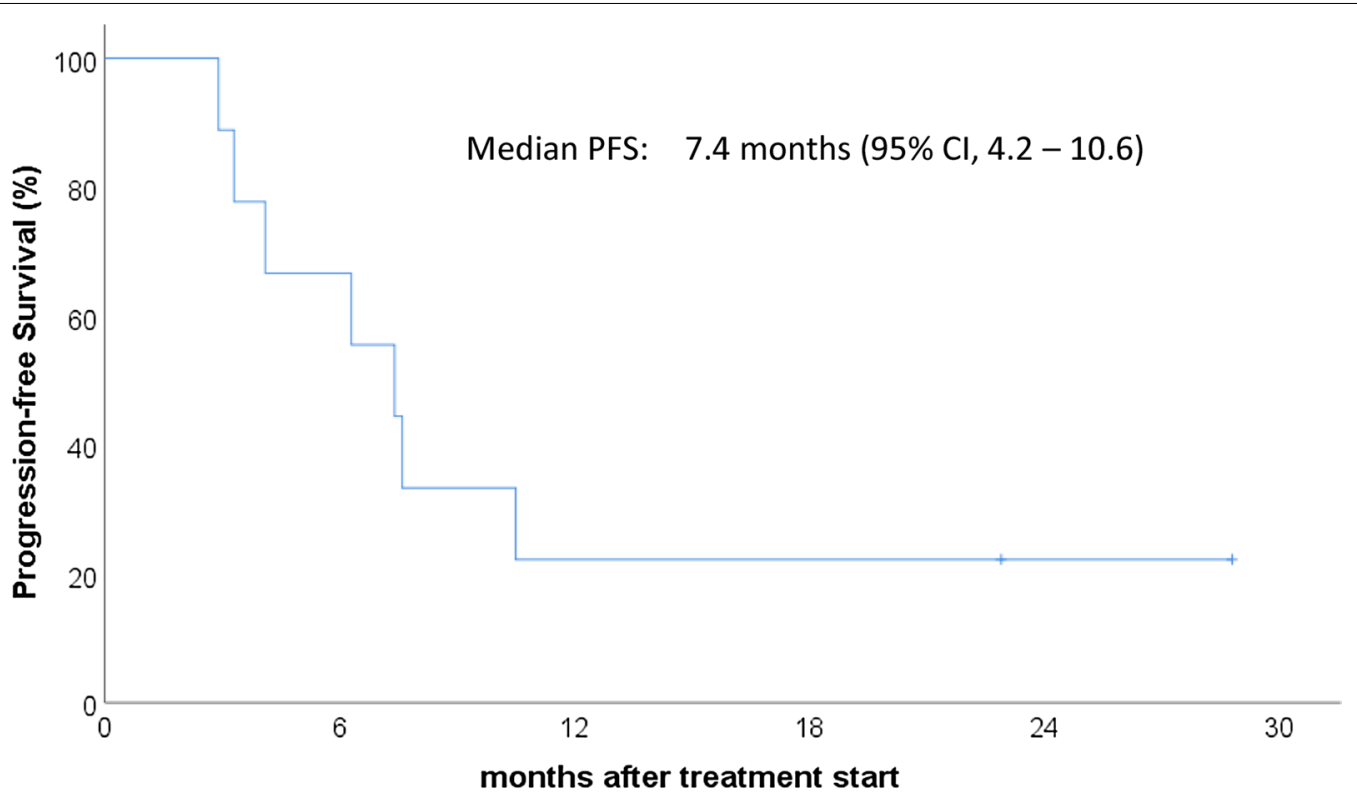

Fig. 4 Progression-free survival

study treated advanced HCC with RT and sunitinib reported objective response rate of $74 \%$ and a median survival of 16 months [50], which was compatible with the result of several phase I or II studies using sorafenib plus RT $[35,51]$. RT in combination with effective systemic therapy may possibly exert the effect of spatial cooperation which may be translated to improved PFS and even OS. Our present study showed an acceptable PFS and impressive OS for advanced HCC treated with the combination strategy. However, due to only small cohort of patients, the efficacy reported in our phase I study should be interpreted with caution. Further phase II or even phase III study is required to adequately evaluate the efficacy. We are planning to conduct a phase 
II trial investigating the efficacy of this combination strategy.

Since regorafenib and lenvatinib were both proved as effective treatment for HCC $[31,32]$, the combination of RT with these relatively new agents could also be studied in the setting of clinical trial [52]. Adverse effects caused by regorafenib are serious concern because a substantial portion of HCC patients cannot well tolerate even regorafenib monotherapy [31]. Lenvatinib could be a better candidate to try a combination treatment with RT because many patients can better tolerate lenvatinib monotherapy as compared with sorafenib [32]. Several other new treatments for advanced HCC emerge recently, including ramucirumab or immunotherapy with immune checkpoint inhibitors. Various combination treatments are worthy of further research [52].

\section{Conclusions}

Axitinib in combination with RT for advanced HCC is well tolerated with an axitinib MTD of $3 \mathrm{mg}$ twice daily in this study. Some patients experienced tumor response to the protocol treatment, even with low dose of axitinib. However, the outcome analysis should be interpreted with caution due to the small total cohort.

\section{Abbreviations}

HCC: Hepatocellular carcinoma; MTD: Maximum tolerated dose; RT: Radiotherapy; IMRT: Intensity-modulated radiotherapy; IGRT: Image-guided radiotherapy; SABR: Stereotactic ablative body radiotherapy; DLT: Dose-limiting toxicity; RFA: Radiofrequency ablation; TACE: Transarterial chemoembolization; VEGF: Vascular endothelial growth factor; RCC: Renal cell carcinoma; ORR: Overall response rate; OS: Overall survival; PFS: Progression free survival; RECIST: Response evaluation criteria in solid tumors; AFP: Alpha-fetoprotein; ALK-P: Alkaline phosphatase; CR: Complete responses; PR: Partial responses.
\end{abstract}

\section{Acknowledgements}

We would like to thank all the investigators and patients.

\section{Authors' contributions}

KLY, YML and KHC conceived the study; KLY, MSC, HLK and YYH collected data; KLY and SCH performed statistical analyses and interpreted data; KLY wrote manuscript; KHC provided critical review and revision of manuscript. All authors reviewed and approved the final manuscript.

\section{Funding}

This study was supported by grants from the Shin Kong Wu Ho-Su Memorial Hospital, Taipei, Taiwan (No. SKH-8302-106-DR-27).

\section{Availability of data and materials}

The datasets used and/or analyzed during the current study are available from the corresponding author on reasonable request.

\section{Ethics approval and consent to participate}

This phase I study was approved by the institutional review board of Shin Kong Wu Ho-Su Memorial Hospital (No. 20150704 M).

\section{Consent for publication}

Consent for publication was obtained.

\section{Competing interests}

The authors declare no competing interests.

\section{Author details}

${ }^{1}$ Department of Radiation Therapy and Oncology, Shin Kong Wu Ho-Su Memorial Hospital, Shih-Lin District, No. 95, Wen-Chang Road, Taipei City 111 , Taiwan. ${ }^{2}$ School of Medicine, Fu Jen Catholic University, No. 510, Chung-Cheng Road, Hsin-Chuang, New Taipei City, Taiwan. ${ }^{3}$ Division of Gastroenterology, Department of Internal Medicine, Shin Kong Wu Ho-Su Memorial Hospital, Taipei City, Taiwan. ${ }^{4}$ Department of Biomedical Imaging and Radiological Sciences, National Yang-Ming University, No. 155, Sec. 2, Linong Street, Beitou District, Taipei City, Taiwan.

Received: 25 June 2020 Accepted: 26 December 2020

Published online: 20 January 2021

\section{References}

1. Curley SA, Izzo F, Ellis LM, Vauthey JN, Vallone P. Radiofrequency ablation of hepatocellular cancer in 110 patients with cirrhosis. Ann Surg. 2000;232(3):381.

2. Machi J, Bueno RS, Wong LL. Long-term follow-up outcome of patients undergoing radiofrequency ablation for unresectable hepatocellular carcinoma. World J Surg. 2005;29(11):1364-73.

3. Llovet JM, Real MI, Montaña X, Planas R, Coll S, Aponte J, et al. Arterial embolisation or chemoembolisation versus symptomatic treatment in patients with unresectable hepatocellular carcinoma: a randomised controlled trial. Lancet. 2002;359(9319):1734-9.

4. Lo CM, Ngan H, Tso WK, Liu CL, Lam CM, Poon RTP, et al. Randomized controlled trial of transarterial lipiodol chemoembolization for unresectable hepatocellular carcinoma. Hepatology. 2002;35(5):1164-71.

5. Lu DS, Yu NC, Raman SS, Lassman C, Tong MJ, Britten C, et al. Percutaneous radiofrequency ablation of hepatocellular carcinoma as a bridge to liver transplantation. Hepatology. 2005;41(5):1130-7.

6. Koda M, Ueki M, Maeda Y, Mimura K-I, Okamoto K, Matsunaga Y, et al. The influence on liver parenchymal function and complications of radiofrequency ablation or the combination with transcatheter arterial embolization for hepatocellular carcinoma. Hepatol Res. 2004;29(1):18-23.

7. Raoul J-L, Sangro B, Forner A, Mazzaferro V, Piscaglia F, Bolondi L, et al. Evolving strategies for the management of intermediate-stage hepatocellular carcinoma: available evidence and expert opinion on the use of transarterial chemoembolization. Cancer Treat Rev. 2011;37(3):212-20.

8. Lencioni R, Petruzzi P, Crocetti L, editors. Chemoembolization of hepatocellular carcinoma. Seminars in interventional radiology; 2013: Thieme Medical Publishers.

9. N'Kontchou G, Mahamoudi A, Aout M, Ganne-Carrié N, Grando V, Coderc E, et al. Radiofrequency ablation of hepatocellular carcinoma: long-term results and prognostic factors in 235 Western patients with cirrhosis. Hepatology. 2009;50(5):1475-83.

10. Ben-Josef E, Normolle D, Ensminger WD, Walker S, Tatro D, Ten Haken RK, et al. Phase II trial of high-dose conformal radiation therapy with concurrent hepatic artery floxuridine for unresectable intrahepatic malignancies. J Clin Oncol. 2005;23(34):8739-47.

11. Regina VT, Hawkins M, Lockwood G, Kim JJ, Cummings B, Knox J, et al. Phase I study of individualized stereotactic body radiotherapy for hepatocellular carcinoma and intrahepatic cholangiocarcinoma. J Clin Oncol. 2008;26(4):657-64.

12. Mornex F, Girard N, Beziat C, Kubas A, Khodri M, Trepo C, et al. Feasibility and efficacy of high-dose three-dimensional-conformal radiotherapy in cirrhotic patients with small-size hepatocellular carcinoma non-eligible for curative therapies - mature results of the French Phase II RTF-1 trial. Int J Radiat Oncol Biol Phys. 2006;66(4):1152-8.

13. Seong J, Lee IJ, Shim SJ, Lim DH, Kim TH, Kim JH, et al. A multicenter retrospective cohort study of practice patterns and clinical outcome on radiotherapy for hepatocellular carcinoma in Korea. Liver Int. 2009;29(2):147-52.

14. Liang SX, Zhu XD, Lu HJ, Pan CY, Li FX, Huang QF, et al. Hypofractionated three-dimensional conformal radiation therapy for primary liver carcinoma. Cancer. 2005;103(10):2181-8.

15. Liu M-T, Li S-H, Chu T-C, Hsieh C-Y, Wang A-Y, Chang T-H, et al. Threedimensional conformal radiation therapy for unresectable hepatocellular carcinoma patients who had failed with or were unsuited for transcatheter arterial chemoembolization. Jpn J Clin Oncol. 2004;34(9):532-9. 
16. Seong J, Park HC, Han KH, Chon CY. Clinical results and prognostic factors in radiotherapy for unresectable hepatocellular carcinoma: a retrospective study of 158 patients. Int J Radiat Oncol Biol Phys. 2003;55(2):329-36.

17. Zeng Z-C, Tang Z-Y, Fan J, Zhou J, Qin L-X, Ye S-L, et al. A comparison of chemoembolization combination with and without radiotherapy for unresectable hepatocellular carcinoma. Cancer J. 2004;10(5):307-16.

18. Li B, Yu J, Wang L, Li C, Zhou T, Zhai L, et al. Study of local three-dimensional conformal radiotherapy combined with transcatheter arterial chemoembolization for patients with stage III hepatocellular carcinoma. Am J Clin Oncol. 2003;26(4):e92-9.

19. Guo W-J, Yu E-X, Liu L-M, Li J, Chen Z, Lin J-H, et al. Comparison between chemoembolization combined with radiotherapy and chemoembolization alone for large hepatocellular carcinoma. World J Gastroenterol. 2003;9(8):1697-701.

20. Cheng JC-H, Chuang VP, Cheng SH, Huang AT, Lin Y-M, Cheng T-I, et al. Local radiotherapy with or without transcatheter arterial chemoembolization for patients with unresectable hepatocellular carcinoma. Int J Radiat Oncol Biol Phys. 2000:47(2):435-42.

21. Shim SJ, Seong J, Han KH, Chon CY, Suh CO, Lee JT. Local radiotherapy as a complement to incomplete transcatheter arterial chemoembolization in locally advanced hepatocellular carcinoma. Liver Int. 2005;25(6):1189-96.

22. McIntosh A, Hagspiel KD, Al-Osaimi AM, Northup P, Caldwell S, Berg C, et al. Accelerated treatment using intensity-modulated radiation therapy plus concurrent capecitabine for unresectable hepatocellular carcinoma. Cancer. 2009;115(21):5117-25.

23. Kim TH, Kim DY, Park J-W, Kim YI, Kim SH, Park HS, et al. Three-dimensional conformal radiotherapy of unresectable hepatocellular carcinoma patients for whom transcatheter arterial chemoembolization was ineffective or unsuitable. Am J Clin Oncol. 2006;29(6):568-75.

24. Chen CP. Role of radiotherapy in the treatment of hepatocellular carcinoma. J Clin Transl Hepatol. 2019;7(2):183.

25. Baumann M, Krause M, Overgaard J, Debus J, Bentzen SM, Daartz J, et al. Radiation oncology in the era of precision medicine. Nat Rev Cancer. 2016;16(4):234.

26. Citrin DE. Recent developments in radiotherapy. N Engl J Med. 2017;377(11):1065-75

27. Shanker MD, Liu HY, Lee YY, Stuart KA, Powell EE, Wigg A, et al. Stereotactic radiotherapy for hepatocellular carcinoma: expanding the multidisciplinary armamentarium. J Gastroenterol Hepatol. 2020.

28. Schwarz RE, Abou-Alfa GK, Geschwind JF, Krishnan S, Salem R, Venook AP. Nonoperative therapies for combined modality treatment of hepatocellular cancer: expert consensus statement. HPB. 2010;12(5):313-20.

29. Llovet JM, Ricci S, Mazzaferro V, Hilgard P, Gane E, Blanc J-F, et al. Sorafenib in advanced hepatocellular carcinoma. N Engl J Med. 2008;359(4):378-90.

30. Cheng A-L, Kang Y-K, Chen Z, Tsao C-J, Qin S, Kim JS, et al. Efficacy and safety of sorafenib in patients in the Asia-Pacific region with advanced hepatocellular carcinoma: a phase III randomised, double-blind, placebocontrolled trial. Lancet Oncol. 2009;10(1):25-34.

31. Bruix J, Qin S, Merle P, Granito A, Huang Y-H, Bodoky G, et al. Regorafenib for patients with hepatocellular carcinoma who progressed on sorafenib treatment (RESORCE): a randomised, double-blind, placebo-controlled, phase 3 trial. Lancet. 2017:389(10064):56-66.

32. Kudo M, Finn RS, Qin S, Han K-H, Ikeda K, Piscaglia F, et al. Lenvatinib versus sorafenib in first-line treatment of patients with unresectable hepatocellular carcinoma: a randomised phase 3 non-inferiority trial. Lancet. 2018;391(10126):1163-73.

33. Wada Y, Takami Y, Matsushima H, Tateishi M, Ryu T, Yoshitomi M, et al. The safety and efficacy of combination therapy of sorafenib and radiotherapy for advanced hepatocellular carcinoma: a retrospective study. Internal Med. 2018:9826-17.

34. Cha J, Seong J, Lee IJ, Kim JW, Han K-H. Feasibility of sorafenib combined with local radiotherapy in advanced hepatocellular carcinoma. Yonsei Med J. 2013;54(5):1178-85.

35. Chen S-W, Lin L-C, Kuo Y-C, Liang J-A, Kuo C-C, Chiou J-F. Phase 2 study of combined sorafenib and radiation therapy in patients with advanced hepatocellular carcinoma. Int J Radiat Oncol Biol Phys. 2014;88(5):1041-7.
36. Rini BI, Escudier B, Tomczak P, Kaprin A, Szczylik C, Hutson TE, et al. Comparative effectiveness of axitinib versus sorafenib in advanced renal cell carcinoma (AXIS): a randomised phase 3 trial. Lancet. 2011;378(9807):1931-9.

37. Kang Y-K, Yau T, Park J-W, Lim H, Lee T-Y, Obi S, et al. Randomized phase II study of axitinib versus placebo plus best supportive care in secondline treatment of advanced hepatocellular carcinoma. Ann Oncol. 2015;26(12):2457-63.

38. McNamara MG, Le LW, Horgan AM, Aspinall A, Burak KW, Dhani N, et al. A phase II trial of second-line axitinib following prior antiangiogenic therapy in advanced hepatocellular carcinoma. Cancer. 2015;121(10):1620-7.

39. Rao SS, Thompson C, Cheng J, Haimovitz-Friedman A, Powell SN, Fuks Z, et al. Axitinib sensitization of high single dose radiotherapy. Radiother Oncol. 2014;111(1):88-93.

40. Hillman GG, Lonardo F, Hoogstra DJ, Rakowski J, Yunker CK, Joiner MC, et al. Axitinib improves radiotherapy in murine xenograft lung tumors. Transl Oncol. 2014;7(3):400-9.

41. Eisenhauer EA, Therasse P, Bogaerts J, Schwartz LH, Sargent D, Ford R, et al. New response evaluation criteria in solid tumours: revised RECIST guideline (version 1.1). Eur J Cancer. 2009;45(2):228-47.

42. Dings RP, Loren M, Heun H, McNiel E, Griffioen AW, Mayo KH, et al. Scheduling of radiation with angiogenesis inhibitors anginex and Avastin improves therapeutic outcome via vessel normalization. Clin Cancer Res. 2007;13(11):3395-402.

43. Geng L, Donnelly E, McMahon G, Lin PC, Sierra-Rivera E, Oshinka H, et al. Inhibition of vascular endothelial growth factor receptor signaling leads to reversal of tumor resistance to radiotherapy. Can Res. 2001;61(6):2413-9.

44. Lima ABC, Macedo LT, Sasse AD. Addition of bevacizumab to chemotherapy in advanced non-small cell lung cancer: a systematic review and meta-analysis. PloS ONE. 2011;6(8).

45. Nieder C, Wiedenmann N, Andratschke N, Molls M. Current status of angiogenesis inhibitors combined with radiation therapy. Cancer Treat Rev. 2006;32(5):348-64.

46. Teicher BA, Holden SA, Ara G, Dupuis NP, Liu F, Yuan J, et al. Influence of an anti-angiogenic treatment on $9 \mathrm{~L}$ gliosarcoma: oxygenation and response to cytotoxic therapy. Int J Cancer. 1995;61(5):732-7.

47. Lee C-G, Heijn M, di Tomaso E, Griffon-Etienne G, Ancukiewicz M, Koike C, et al. Anti-vascular endothelial growth factor treatment augments tumor radiation response under normoxic or hypoxic conditions. Can Res. 2000;60(19):5565-70.

48. Rugo HS, Herbst RS, Liu G, Park JW, Kies MS, Steinfeldt HM, et al. Phase I trial of the oral antiangiogenesis agent AG-013736 in patients with advanced solid tumors: pharmacokinetic and clinical results. J Clin Oncol. 2005;23(24):5474-83.

49. Rixe O, Bukowski RM, Michaelson MD, Wilding G, Hudes GR, Bolte O, et al. Axitinib treatment in patients with cytokine-refractory metastatic renalcell cancer: a phase II study. Lancet Oncol. 2007;8(11):975-84.

50. Chi K-H, Liao C-S, Chang C-C, Ko H-L, Tsang Y-W, Yang K-C, et al. Angiogenic blockade and radiotherapy in hepatocellular carcinoma. Int J Radiat Oncol Biol Phys. 2010;78(1):188-93.

51. Dawson L, Brade A, Cho C, Kim J, Brierley J, Dinniwell R, et al. Phase I study of sorafenib and SBRT for advanced hepatocellular carcinoma. Int J Radiat Oncol Biol Phys. 2012;84(3):S10-1.

52. Keane FK, Hong TS, Zhu AX, editors. Evolving systemic therapy in hepatocellular carcinoma: current management and opportunities for integration with radiotherapy. Seminars in radiation oncology; 2018: Elsevier.

\section{Publisher's Note}

Springer Nature remains neutral with regard to jurisdictional claims in published maps and institutional affiliations. 